\title{
Contribuições da consultoria colaborativa para a inclusão de pessoas com deficiência intelectual
}

\author{
Sandra Lúcia Silva Araújo* \\ Maria Amélia Almeida**
}

\section{Resumo}

Neste artigo procuraremos mostrar as possíveis contribuições da consultoria colaborativa para a inclusão de alunos com deficiência intelectual, por meio de uma análise reflexiva com base na literatura pertinente. Em um crescente processo de inclusão escolar, o ingresso de pessoas com deficiência intelectual tem representado um número significativo não somente no ambiente escolar como também no atendimento educacional especializado. A inclusão desses alunos tem despertado uma atenção especial assim como a necessidade de fazer ajustes e reflexões. Uma contribuição nesse sentido é a prática da consultoria colaborativa, que pode ser considerada como uma parceria entre professor de educação especial, ensino comum e outros profissionais. A efetivação dessa parceria pode trazer importantes contribuições para a família, para a escola e para a comunidade. Neste sentido, a consultoria colaborativa pode ser uma alternativa para a inclusão de pessoas com deficiência intelectual, não apenas no âmbito da intervenção mas também no âmbito da prevenção, da reflexão e da transformação do meio escolar. Procuraremos, assim, fazer algumas reflexões sobre o tema, tomando como base a literatura pertinente.

Palavras-chave: Consultoria colaborativa; Inclusão escolar; Deficiência intelectual.

* Pós-doutoranda pelo Departamento de Psicologia - CECH - Universidade Federal de São Carlos, São Carlos, São Paulo - Brasil. Agência de Fomento: FAPESP - Programa Ensino Público.

** Professora Doutora da Universidade Federal de São Carlos, São Carlos, São Paulo - Brasil. 


\title{
Contributions of collaborative consultation for the inclusion of students with intellectual disabilities
}

\begin{abstract}
In this article we aim to show the possible contributions of collaborative consultation for the inclusion of students with intellectual disabilities, through a reflective analysis based on relevant literature. In a growing school inclusion process, the entrance of students with intellectual disabilities has represented a significant number not only at school but also in specialized educational services. The inclusion of these students has attracted special attention as well as the necessity to make adjustments and reflections. A contribution in this direction is the practice of collaborative consultation, which can be considered as a partnership between special education teacher, regular teacher and other professionals. The effectiveness of this partnership can bring important contributions to family, school and community. In this sense, collaborative consultation can be an alternative to the inclusion of people with intellectual disabilities, not only in the context of the intervention but also in the prevention, reflection and transformation of the school environment. We seek, therefore, to make some reflections on the subject, based on the literature.
\end{abstract}

Keywords: Collaborative consultation; School inclusion; Intellectual disabilities.

\section{Introdução}

A inclusão de alunos com necessidades educacionais especiais têm, de um modo geral, aumentado gradativamente no sistema público brasileiro (BRASIL, 2009b), requerendo a atenção de pesquisadores e autoridades para essa temática. Dentre as várias necessidades especiais presentes no meio escolar, a deficiência intelectual tem despertado uma atenção maior, considerando sua maior complexidade principalmente no tocante à organização das situações de ensino-aprendizagem bem como a aspectos avaliativos.

Dentro de nossa legislação mais recente, a deficiência intelectual é apontada como parte do público alvo da Educação Especial, devendo receber o Atendimento Educacional Especializado, em salas de recursos multifuncionais, que por lei, deve ocorrer no contraturno e preferencialmente na rede pública.

Dentre os vários alunos com necessidades educacionais especiais que são encaminhados para esse atendimento, a maior parte deles corresponde ao alunado com Deficiência Intelectual (BRASIL, 2009b). Embora, em muitos casos, não exista um diagnóstico que diferencie dificuldades de aprendizagem de deficiência intelectual, esses alunos são encaminhados para a Educação Especial, mediante queixas de professores; as queixas baseiam-se no fato desses alunos possuírem um grande déficit de aprendizagem comparado a outras crianças, principalmente na área da leitura e escrita. Embora não existam dados oficiais até o momento, sabe-se pelo acompanhamento da realidade escolar que esta tem sido a maior demanda para a Educação Especial. 
Com isto e com o crescente processo de inclusão escolar, o campo de possibilidades de atuação da Educação Especial tende a se ampliar, atuação esta que tem como objetivo dar apoio pedagógico especializado. No entanto, o que tem ocorrido, em muitos casos, é a existência de uma forma de intervenção pautada em um modelo clínico, com o fim de remediar os problemas de aprendizagem; modelo este, onde é escasso ou nulo um trabalho de parceria colaborativa.

Neste sentido, a consultoria colaborativa - que é o compartilhamento do trabalho (planejamento, avaliação, expectativas) entre um especialista e o professor de Educação Comum - tem sido apontada com um dos componentes para uma inclusão bem sucedida. Como veremos adiante, o trabalho colaborativo pode ser muito importante não somente para fazer intervenções quanto às dificuldades de aprendizagem do aluno mas também no sentido de unir forças para realizar conquistas políticosociais.

Este artigo trata, portanto, das contribuições da consultoria colaborativa para a inclusão de pessoas com deficiência intelectual. Para falarmos sobre isso, é necessário que façamos uma breve explanação sobre a trajetória educacional de pessoas com deficiência intelectual.

\section{A trajetória educacional das pessoas com deficiência intelectual}

Ao longo da história, a concepção de deficiência intelectual sofreu várias mudanças, partindo, como veremos, de uma visão médica, indo para uma visão psicológica para, posteriormente, construir-se uma visão mais ecológica e social, enfatizando o apoio educacional.

Atualmente, a definição de deficiência intelectual mais aceita e difundida internacionalmente é a que propõe a American Association on Intellectual and Developmental Disabilities (AAIDD, 2010). Em nosso país, ela é frequentemente citada em publicações e em documentos oficiais.

Segundo a AAIDD, a deficiência intelectual pode ser definida como:

[...] uma incapacidade caracterizada por importantes limitações tanto no funcionamento intelectual quanto no comportamento adaptativo, expresso nas habilidades adaptativas conceituais, sociais e práticas. Essa deficiência tem início antes dos 18 anos. (AAIDD, 2010, tradução nossa)

Com esta definição, a deficiência (disability) pode ser entendida como uma limitação que pode ocasionar alguma desvantagem no funcionamento intelectual (na capacidade de racionar, pensar e planejar) e no comportamento adaptativo da pessoa com deficiência intelectual.

O comportamento adaptativo é entendido como um amplo conjunto que compreende as seguintes habilidades: Habilidades Conceituais (ex: relacionadas à leitura e escrita, localização espacial, uso do dinheiro); Habilidades Sociais (saber relacionar-se com seus pares, entender regras, ter responsabilidade) e Habilidades Práticas (ex:ativi-

Revista Educação Especial | v. 27 | n. 49 | p. 341-352| maio/ago. 2014

Santa Maria 
dades de vida autônoma como tomar banho, comer, vestir-se, ter cuidado com objetos perigosos) (AAIDD, 2010).

A AAIDD (2010) ainda recomenda ao menos nove áreas em que a Educação Especial deve atuar: 1) desenvolvimento humano, 2) ensino e educação, 3) vida em família, 4) vida em comunidade, 5) emprego, 6) saúde e segurança, 7) comportamento; 8) sociabilidade e 9) proteção e direitos.

Podemos perceber, então, que em decorrência de várias mudanças de concepções e de entendimento da deficiência intelectual, temos hoje uma definição que propõe um modelo ecológico, que compreende a deficiência dentro de um contexto social, cultural e familiar. Assim sendo, o foco não é mais as limitações decorrentes da deficiência intelectual mas as possibilidades que pode vir a ter por meio dos apoios dados pela Educação Especial.

Não apenas a concepção de deficiência intelectual foi modificada ao longo da história mas, também as suas possibilidades educacionais. Elas eram muito restritas em outras épocas e contextos. Falaremos brevemente sobre elas.

A literatura pertinente (BEYER, 2006; MAZZOTTA, 2003; PESSOTI, 1984), nos mostra que as pessoas com deficiência intelectual assim como aquelas com outras deficiências eram condenadas ao abandono ou destinadas à morte.

Com a propagação do cristianismo, houve uma mudança de percepção: a de que a deficiência era decorrente de fatores religiosos como castigo ou expiação e, por esse motivo, essas pessoas deveriam não mais ser abandonadas mas acolhidas em asilos ou instituições mantidas pela Igreja.

Na idade moderna e com o avanço da medicina, já se pensava em várias possíveis explicações para a deficiência intelectual. Apesar desses pequenos avanços, infelizmente, nessa época, ainda havia muita confusão entre deficiência intelectual e transtornos mentais, resultando no internamento em hospitais psiquiátricos de muitas pessoas com deficiência intelectual. No final do séc. XVIII e no início do séc. XIX destaca-se o brilhante trabalho de Itard (1774-1838) realizado com Vitor, o menino de Aveyron, representando o surgimento da Educação Especial e sendo o ponto de partida para futuros trabalhos nessa direção realizados por Seguin e, posteriormente, por Montessori (BEYER, 2006; MAZZOTTA, 2003; PESSOTI, 1984).

Desses trabalhos iniciais, passou-se cada vez mais a acreditar que as pessoas com deficiência intelectual precisariam de Educação Especial para suprir suas necessidades educacionais. Nesse sentido, a Educação Especial foi se consolidando e passando a tomar forma como uma importante área de pesquisa. Acompanhando esse desenrolar, foram surgindo escolas e classes especiais até que em alguns países começou a se pensar que as pessoas com deficiência de modo geral deveriam ser incluídas no ensino regular.

Um importante marco para essa proposta inclusiva foi a "Declaração de Salamanca" (BRASIL, 1994), cuja convenção se deu na cidade de Salamanca/Espanha, apontando que os governantes devem matricular "todas as crianças em escolas re- 
gulares, a menos que existam fortes razões para agir de outra forma" (BRASIL, 1994, p. 2). Essa declaração foi um marco histórico para que se pensasse concretamente em uma proposta de educação inclusiva e para que alavancasse outras declarações e convenções. Embora cada país tenha se organizado de forma diferente, temos hoje um movimento mundial pela inclusão escolar de pessoas com deficiência.

O Brasil também tem acompanhado essa trajetória internacional. Tivemos, inicialmente, um período de institucionalização em asilos e hospitais psiquiátricos e, posteriormente o surgimento de escolas e classes especiais (JANNUZZI, 2012). Ao contrário de alguns países, a educação especial começou a se solidificar na década de 50, com o surgimento da primeira APAE e na década de 60, com a Lei de Diretrizes e Bases da Educação Nacional (LDBN) 4024/61, tendo um artigo referente à educação de excepcionais. A promulgação desse artigo na LDB juntamente com o movimento de pais foi uma força propulsora para que fossem criados órgãos e secretarias ligadas ao Ministério de Educação assim como campanhas em prol da pessoa com deficiência. Tais conjuntos de ações nos mostram que a Educação Especial é ainda recente no Brasil e fortemente marcada por entidades filantrópicas e por movimentos de pais, sendo esta uma peculiaridade de nosso país.

A educação de pessoas com deficiência continuou presente na LDBEN 5692/71 e, posteriormente, em nossa atual LDBEN 9.394/96 (BRASIL, 2006), em cujo artigo 58 é apontado que a Educação Especial é uma "modalidade de educação escolar, oferecida preferencialmente na rede regular de ensino, para educandos portadores de necessidades especiais" (BRASIL, 1996, p. 19).

A partir da atual LDBEN, começou-se a consolidar uma proposta de educação inclusiva mas foi com a Política Nacional de Educação Especial na Perspectiva da Educação Inclusiva (BRASIL, 2008) que isso se deu mais efetivamente, colocando a questão da inclusão de pessoas com deficiência no ensino regular e falando efetivamente sobre o Atendimento Educacional Especializado que deve ser realizado no contraturno, em salas de recurso multifuncionais. Esta proposta de Atendimento Educacional Especializado (AEE) foi regulamentado pelo Parecer CNE/CEB n. 13/2009 (BRASIL, 2009a) e pelo Decreto 7.611/2011 (BRASIL, 2011), notando-se, nesse último, a força do movimento de pais.

Apesar de termos uma legislação específica, a inclusão de pessoas com deficiência intelectual encontra ainda muitos desafios e são necessárias ainda muitas conquistas em várias áreas. São necessários mais investimentos e qualidade de serviço na educação como um todo e não apenas na Educação Especial permeando questões como: formação de professores, melhores condições de trabalho docente, sala de aula com número menor de alunos, recursos tecnológicos e uma escola com diferentes situações de aprendizagem, não restrita apenas à sala de aula e livro didático.

Acreditamos que a escola como um todo deve ter qualidade considerando-se que esse aluno faz parte dessa instituição. Isso quer dizer que esse aluno pertence à escola e não apenas ao quadro de alunos da Educação Especial. Nesse sentido, se a instituição é falha, a inclusão desse aluno também não será adequada o que exige que pensemos em melhorias na educação como um todo.

Revista Educação Especial | v. 27 | n. 49 | p. 341-352| maio/ago. 2014

Santa Maria 
No caso específico do aluno com deficiência intelectual, os problemas mais mencionados e enfrentados no processo de inclusão escolar consistem em como trabalhar os conteúdos escolares e em como avaliar esse aluno quando ele encontra-se, principalmente, em ciclos de estudo posteriores e não possui leitura e escrita; outra questão refere-se à como conduzir e intervir em casos em que esse aluno manifesta comportamentos desafiadores. São problemas que devem ser pensados no âmbito político e que também podem ser solucionados ou amenizados quando existe parceria com outros profissionais além dos professores de educação comum e especial. A parceria com a Universidade, como veremos em outro momento, poder ser também muito enriquecedora.

Mediante esses questionamentos, apontamos como muito válidas ações e pesquisas voltadas principalmente para a temática das adequações curriculares, do currículo funcional na escola comum assim como das questões comportamentais.

Neste sentido, a consultoria colaborativa pode ser uma alternativa para a inclusão de pessoas com deficiência intelectual, não apenas no âmbito da intervenção mas também no âmbito da prevenção, da reflexão e da transformação do meio escolar.

\section{A consultoria colaborativa}

A consultoria colaborativa é definida por alguns autores como "um processo interativo que capacita grupos de pessoas com experiências diversas a gerar soluções criativas para problemas definidos mutuamente" (IDOL; NEVIN; PAOLUCCI-WHITCOMB, 2000, p. 1).

Para Kampwirth (2003) a consultoria colaborativa é um processo no qual um consultor treinado na realidade escolar trabalha de modo igualitário, em uma relação não hierárquica com os demais membros, a fim de tomar decisões juntos e realizar planos visando à melhoria do aluno que necessita de intervenção.

Diferentemente de outras formas de consultoria, a consultoria colaborativa visa trabalhar em condições de igualdade entre todos os membros, somando experiências, buscando soluções, planejando e avaliando juntos. Nesse sentido, é fundamental o respeito mútuo, o diálogo, o não uso de jargões, o desejo de aprender com o outro e a disponibilidade para dar e receber sugestões sem julgamentos e sem defensiva (PALCHES, 2008).

De acordo com Gately e Gately (2001), o trabalho colaborativo envolve três estágios: 1. Estágio Inicial - caracterizado por conversas formais e pouco freqüentes como também uma certa inibição; 2. Estágio de Compromisso - há um maior engajamento, mais comunicação e troca de experiências; 3. Estágio Colaborativo - a interação é mais solta, espontânea e predomina o humor.

Para que se chegue a este estágio e para que se efetive um trabalho colaborativo bem sucedido, é necessário que se estabeleçam algumas etapas ou estágios. Com relação a isso, Idol, Nevin e Paolucci-Whitcomb (2000) estabelecem seis estágios no processo de consultoria colaborativa: 1) Ganhar entrada e estabelecer objetivos da equipe - consiste em criar um primeiro vínculo com a equipe de trabalho, definindo metas, 
papéis e pontuando objetivos e benefícios do trabalho colaborativo; 2) Identificação do Problema - há um esforço da equipe em definir de modo claro e preciso qual é o problema que necessita ser solucionado; 3) Intervenções/Recomendações - a equipe discute possíveis soluções, alternativas de intervenção e planejam como se dará sua aplicação; 4) Implementação das recomendações - as estratégias e as intervenções são implementadas a fim de solucionar o problema; 5) Avaliação - os resultados da intervenção são avaliados em termos de sucessos obtidos e de pontos que necessitam ser revistos; 6) Prosseguimento - a equipe avalia seu trabalho de parceria colaborativa, comemorando os sucessos obtidos, reestruturando o trabalho, verificando se a consultoria deve continuar e formulando novos objetivos.

A consultoria colaborativa geralmente envolve o consultor, a equipe e o aluno; esta relação, no entanto, pode estender-se para a família, a comunidade e outras pessoas/profissionais.

Este tipo de consultoria não apenas visa encontrar soluções a curto prazo mas também a longo prazo, evitando o surgimento de outros problemas. Esta é a opinião de Jordan (1994) que considera a consultoria colaborativa com uma ferramenta de promoção da prática na sala de aula, compreendendo três objetivos: solucionar um problema imediato relacionado à situação de aprendizagem pontuada pelo colega ou equipe; ajudar a desenvolver no colega ou na equipe conhecimentos e habilidades que os permita lidar com problemas semelhantes no futuro e, mudar o modo pelo qual as pessoas trabalham, ou seja, suas concepções e crenças com relação à pessoa com necessidades educacionais especiais. A consultoria colaborativa permite, desse modo, não apenas resolver problemas atuais mas prevenir problemas futuros e capacitar o professor/a equipe a lidar com eles futuramente.

Além destes benefícios, a literatura tem apontado outros benefícios da consultoria colaborativa. Para Kampwirth (2003) esta colaboração possibilita, dentre outras coisas, uma aproximação do trabalho entre o professor de educação comum e especial; o apoio dado aos professores que lidam com as dificuldades do aluno; a geração de idéias por meio de um trabalho em conjunto; a melhora dos serviços oferecidos ao aluno. Além disso, a consultoria colaborativa também permite que a equipe adquira domínio nos conteúdos trabalhados; na comunicação interpessoal; na habilidade de solucionar problemas e, nas atitudes intrapessoais (IDOL; NEVIN; PAOLUCCI -WHITCOMB, 2000). Segundo os mesmos autores, "implementar um modelo de consultoria colaborativa pode resultar em uma revolução no modo como as pessoas percebem problemas e geram soluções" (IDOL; NEVIN; PAOLUCCI-WHITCOMB, 2000, p. 289).

Este tipo de consultoria requer trabalho intensivo e treinamento para trabalhar em equipe, tal treinamento inclui a aprendizagem de habilidades sociais e de princípios éticos, como respeito às diferenças culturais. Este trabalho também requer a revisão de certas crenças e conceitos com relação ao ensino comum e especial, levando a uma superação do binômio ensino comum/especial.

Revista Educação Especial | v. 27 | n. 49 | p. 341-352| maio/ago. 2014

Santa Maria 
Como vimos, a literatura estrangeira tem apontado vários benefícios da consultoria colaborativa (JORDAN, 1994; IDOL; NEVIN; PAOLUCCI-WHITCOMB, 2000; KAMPWIRTH, 2003). No Brasil, existem poucas publicações dentro desta temática (ALMEIDA et al., 2007; ALMEIDA et al., 2008; ALMEIDA; ALPINO, 2008; ALMEIDA; ROCHA, 2008; ALPINO, 2008; JESUS, 2007; MENDES; TOYODA; BISACCIONE, 2007; PEREIRA, 2009; ZANATA, 2004), além de algumas iniciativas pioneiras na UFSCarl ${ }^{1}$. Além de serem escassas, as publicações sobre consultoria colaborativa, também, de acordo com Capellini (2005), ainda não há, no Brasil, uma legislação e propostas curriculares que deem subsídios para um trabalho colaborativo como também são escassas as publicações que levantam contribuições da consultoria colaborativa na abordagem das dificuldades de aprendizagem.

\section{A consultoria colaborativa na abordagem da deficiência intelectual}

A consultoria colaborativa, quando bem efetuada, pode oferecer muitas contribuições na inclusão de pessoas com deficiência intelectual (KAMPWIRTH, 2003). Tais contribuições podem vir da parceria entre o professor de sala de aula comum com vários profissionais como fonoaudiólogos, fisioterapeutas, psicólogos, psicopedagogos, terapeutas ocupacionais, dentre outros profissionais. Nestes casos, há uma troca de informações e de experiências entre diversas áreas o que possibilita enriquecer o trabalho com este aluno.

Uma parceria que pode trazer amplos benefícios, e que estaremos mais voltados neste artigo, é a do professor de educação comum com a do professor de educação especial. Por meio deste trabalho, o professor de educação comum participa de vários modos: com sua experiência de ensinar em sala de aula; com o conhecimento da rotina escolar e com conhecimentos sobre conteúdo escolar e sobre como avaliar estes conteúdos. Já o professor de Educação Especial participa com: sua experiência em trabalhar com pessoas com diferentes necessidades educacionais, cujas dificuldades de aprendizagem podem ser mais intensas; com sua experiência em fazer acomodações na sala de aula, no currículo e na avaliação e com seu conhecimento na área de prevenção de deficiências (IDOL; NEVIN; PAOLUCCI-WHITCOMB, 2000).

Juntos os dois professores compartilham suas experiências em domínios diferentes como também compartilham dúvidas, expectativas e frustrações. Este trabalho permite que ambos os profissionais adquiram competências para lidar com problemas atuais e com desafios semelhantes em ocasiões futuras.

No caso da deficiência intelectual, quando há uma efetiva parceria, ambos os profissionais podem encontrar soluções quanto à melhor forma de: intervir nas dificuldades do aluno; no modo de trabalhar o conteúdo escolar; nas acomodações que podem ser feitas na sala de aula; na forma de avaliar o desempenho do aluno; no trabalho em comum com outros professores, com a direção da escola e com a família, e na prevenção de deficiências. Desta forma, as possibilidades de encontrar soluções para as necessidades educacionais do aluno são muito maiores do que no caso de cada profissional trabalhar isoladamente com um vertente do problema. 
Além deste trabalho, a consultoria colaborativa também pode ser uma importante forma de se alcançar conquistas no âmbito político-social. Considerando-se que a deficiência intelectual (quando não vinculadas a causas orgânicas) podem ter uma conotação social e educacional, esta consultoria também deve atuar nestes aspectos.

A atuação nestes âmbitos pode se dar por meio da reflexão na e sobre a ação (SCHÖN, 1992), pela participação/engajamento da comunidade nos problemas escolares, por meio da busca de respaldo legal para assegurar direitos assegurados em leis, pela cobrança junto a representantes dos poderes públicos e por meio de parcerias com órgãos e com a universidade.

Nesse sentido, é de grande valia que a consultoria envolva escola e universidade, conhecimento prático e teórico. Os professores precisam ter espaço para dizer o que pensam, para compartilhar sua prática e a universidade precisa saber ouvi-los, oferecendo-lhes instrumentos para repensar essa prática.

Quanto a isso, realizamos em uma escola pública do interior do estado de São Paulo um projeto que contempla essa parceria entre universidade e escola. Tal projeto, financiado pela FAPESP na modalidade "Ensino Público" (2009/51422-7), visou a efetivação de um programa de consultoria colaborativa para intervenção na área da leitura e escrita (ALMEIDA; ARAÚJO, 2011, 2012). Participaram deste projeto oito professores de Ensino Fundamental, uma professora de Educação Especial e uma pesquisadora da Universidade Federal de São Carlos, sendo que cada professor de Ensino Fundamental teve um aluno alvo com alguma necessidade especial, a maior parte, com deficiência intelectual. Esta equipe reunia-se quinzenalmente para falar sobre cada aluno e sobre as intervenções que foram e que deveriam ser feitas. Procuramos seguir as etapas da consultoria colaborativa apontadas anteriormente como, identificar o problema, pensar em estratégias, aplicá-las e testá-las. Ao longo do projeto pudemos perceber resultados muito positivos como a transição de um estágio inicial no qual havia pouca participação dos professores para um estágio colaborativo (GATELY; GATELY, 2001), no qual os professores passaram a colaborar mais com seus colegas e a confiar mais em sua experiência profissional. Percebemos também que intervenções envolvendo consciência fonológica, estratégias de aprendizagem e desenvolvimento de processos mentais propiciaram melhoras nos desempenhos de nossos alunos alvo nas áreas de leitura e escrita. Além disso, também notamos a importância de algumas adequações curriculares com relação aos conteúdos escolares e com relação à avaliação escolar.

O trabalho colaborativo desenvolvido neste projeto nos proporcionou não apenas mais conhecimentos sobre a deficiência intelectual como também sobre as problemáticas da escola pública e a metodologia de pesquisa-ação colaborativa que utilizamos. Além disso, também nos permitiu levantar discussões no sentido de contextualizar a deficiência intelectual dentro de uma realidade social, percebendo a necessidade de envolver também os âmbitos preventivo e político-social. Percebemos que seria muito importante se a consultoria colaborativa fosse uma realidade na escola pública, envolvendo profissionais de diferentes áreas. Tal colaboração permitiria ao professor sentir-se amparado mediante o processo de inclusão escolar.

Revista Educação Especial | v. 27 | n. 49 | p. 341-352| maio/ago. 2014

Santa Maria 
Nesse sentido, gostaríamos de concluir afirmando que a deficiência intelectual, como área da educação especial, precisa ser abordada considerando três âmbitos: o preventivo, o educacional e o político-social. Para que a deficiência intelectual contemple estes aspectos é imprescindível que haja uma parceria colaborativa entre professor de educação comum e especial, entre universidade e escola, trabalhando juntos, formando outras parcerias e efetivando conquistas.

\section{Referências}

AAIDD. Intellectual disability: definition, classification and systems of supports. llth ed. Washington (DC): American Association on Intellectual and Developmental Disabilities, 2010.

ALMEIDA et al. Parceria colaborativa: descrição de uma experiência entre ensino regular e especial. Revista Educação Especial, v. 29, p. 9-22, 2007.

ALMEIDA, M.A.; ALPINO, A. M. S. Colaboração do fisioterapeuta na promoção da acessibilidade escolar e participação do aluno com paralisia cerebral. Anais do III Congresso Brasileiro de Educação Especial/ IV Encontro da Associação de Pesquisadores em Educação Especial, São Carlos, 2008.

et al. Consultoria colaborativa na visão de professoras do ensino público regular. Anais do III Congresso Brasileiro de Educação Especial/IV Encontro da Associação de Pesquisadores em Educação Especial, São Carlos, 2008.

ALPINO, A. M. S. Consultoria Colaborativa escolar do fisioterapeuta: acessibilidade e participação do aluno com paralisia cerebral em questão. Tese (Doutorado em Educação Especial), 2005, 190p - CECH, UFSCAR, São Carlos, 2008.

ARAÚJO, S.L.S.; ALMEIDA, M. A.; A elaboração e a avaliação de um projeto de consultoria colaborativa para a intervenção em leitura e escrita. Anais do VI Encontro Iberoamericano de Educação (UNESP/ Universidad de Alcalá), Araraquara, 2011.

A elaboração e a avaliação de um projeto de consultoria colaborativa para a intervenção em leitura e escrita. Anais do V Congresso Brasileiro de Educação Especial/VI Encontro da Associação de Pesquisadores em Educação Especial, São Carlos, 2012.

BEYER, H. O. Inclusão e avaliação na escola de alunos com necessidades educacionais especiais. $2^{\underline{a}}$ ed. Porto Alegre: Mediação, 2006

BRASIL. Declaração de Salamanca e linha de ação sobre necessidades educativas especiais. Brasília: UNESCO, 1994.

BRASIL. Ministério da Educação. Lei de Diretrizes e Bases da Educação Nacional, LDB 9.394, de 20 de dezembro de 1996. Brasília, DF, 1996.

. Ministério da Educação. Secretaria de Educação Especial. Política Nacional de Educação Especial na perspectiva da Educação Inclusiva. Brasília, DF, 2008, 19p.

Ministério da Educação. Secretaria de Educação Especial. Parecer CNE/CEB n. 13/2009, de 17 de setembro de 2008. Secretaria de Educação Especial - MEC/SEESP, 2009a, 4p. $\overline{2009 b}$.

Ministério da Educação. Sinopses estatísticas da educação básica/censo escolar. MEC/INEP,

Ministério da Educação. Decreto 7.611/2011, de 17 de novembro de 2011. Secretaria de Educação Continuada, Alfabetização e Diversidade - MEC/SECAD, 2011, 3p.

CAPELLINI, V. L. M. F. Avaliação das possibilidades do ensino colaborativo no processo de inclusão escolar do aluno com deficiência mental. Tese (Doutorado em Educação Especial), 2005, 300p - CECH, UFSCAR, São Carlos, 2005.

GATELY, S.; GATELY Jr, F. J. Understanding coteaching components. Teaching exceptional children, 33(4), 40-7, 2001.

IDOL, L; NEVIN, A.; PAOLUCCI-WHITCOMB, P. Collaborative consultation. 3rd ed. Austin: Pro-ed, 2000 
JANNUZZI, G. A educação do deficiente no Brasil: dos primórdios ao início do século XXI. 3åa ed. rev. Campinas: Editora Autores Associados, 2012.

JESUS, D. M. Vozes e narrativas na ação grupal: trajetórias de formação de professores-pesquisadores na perspectiva da inclusão escolar. In. BAPTISTA, C.R. et al. (Org.) Inclusão, práticas pedagógicas e trajetórias de pesquisa. $1^{\underline{a}}$ ed. Porto Alegre: Mediação, 2007.

JORDAN, A. Skills in collaborative classroom consultation. 1st ed. London, New York: Routledge, 1994.

KAMPWIRTH, T. J. Collaborative consultation in the schools: effective practices for students with learning and behavior problems. 2nd ed. New Jersey: Merril Prentice Hall, 2003.

MAZZOTTA, M. J. S. Educação Especial no Brasil: história e políticas públicas. $4^{a}$ ed. São Paulo: Cortez, 2003.

MENDES, E. G.; TOYODA, C. Y.; BISACCIONE, P. S.O.S. inclusão escolar: avaliação de um programa de consultoria colaborativa com base em diários de campo. In. BAPTISTA, C.R. et al. (Org.) Inclusão, práticas pedagógicas e trajetórias de pesquisa. $1^{\underline{a}}$ ed. Porto Alegre: Mediação, 2007.

PEREIRA, V. A. Consultoria colaborativa na escola: contribuições da psicologia para inclusão escolar do aluno surdo. Tese (Doutorado em Educação Especial), 2009, 164p - CECH, UFSCAR, São Carlos, 2009.

PESSOTI, I. Deficiência mental: da superstição à ciência. 1ª ed. São Paulo: EDUSP, 1984.

SCHÖN, D. A. Formar professores como profissionais reflexivos. In: NÒVOA, A. (Org.) Os professores e sua formação. la ed. Lisboa: Dom Quixote, 1992.

ZANATA, E. M. Práticas pedagógicas inclusivas para alunos surdos numa perspectiva colaborativa. Tese (Doutorado em Educação Especial), 2004, 198p - CECH, UFSCAR, São Carlos, 2004.

Nota

${ }^{1}$ O Programa de Pós-Graduação em Educação Especial da UFSCAR possui uma disciplina específica sobre consultoria colaborativa e um grupo de pesquisa que contempla o assunto.

\section{Correspondência}

Sandra Lucia Silva Araújo - Prefeitura Municipal de Araraquara, EMEF Prof. Waldemar Saffiotti. Rua Mário Barbugli, 1015, Jd. Cruzeiro do Sul, CEP: 14808-378 - Araraquara, São Paulo - Brasil.

E-mail: saneduc@hotmail.com - ameliama@terra.com.br

Recebido em 12 de abril de 2013

Aprovado em 20 de maio de 2013

Revista Educação Especial | v. 27 | n. 49 | p. 341-352| maio/ago. 2014

Santa Maria

Disponível em: <http://www.ufsm.br/revistaeducacaoespecial> 